\title{
Character Displacement in Sphaeroma spp. (Isopoda: Crustacea). II. Competition for Space
}

\author{
J. O. Frier \\ Institute of Ecology and Genetics, University of Aarhus, Ny Munkegade, DK-8000 Aarhus C, Denmark
}

\begin{abstract}
The two sibling isopod species Sphaeroma hookeri and S. rugicauda show divergent character displacement with respect to body size of sympatric populations (Frier, 1979a). The present paper investigates the hypothesis that this displacement causes a relaxation of interspecific competition for space. It provides field evidence of substrate preferences of the various lifecycle stages of isopods and presents experimental evidence for a size-dependent preference for different dimensions of shelter.
\end{abstract}

\section{INTRODUCTION}

Character displacement with respect to body size has been demonstrated in the two isopods Sphaeroma hookeri and S. rugicauda (Frier, 1979a). S. hookeri is smaller, $S$. rugicauda bigger in sympatric populations as compared with allopatric ones. At least three kinds of evidence are required for documenting character displacement (Frier, 1979a): field evidence, experiments revealing the advantage of the displacements in terms of individual fitness, and evidence for the hereditability of the phenomenon.

In the Sphaeroma species studied several different mechanisms can be conceived which explain the size displacements in sympatry. Among the more plausible ones are a relaxed competition for food or space, and a smaller probability for interspecific copulation and precopulation.

The food sources of the isopods concerned are diverse; they comprise decaying organic matter, diatoms, and different macroalgae. The feeding methods are no less diverse; they involve browsing, sediment eating, as well as taking bites of macroalgae. The diversity of food and feeding methods renders the quantification of the food spectrum difficult, and this part of the investigation has not yet produced satisfactory results.

To the extent that the observed divergent displacement is due to a displacement in time it may reflect selection against interspecific matings. This subject is treated in a subsequent paper (Frier, 1979b).
The present paper deals with competition for space between the Sphaeroma species studied. Competition for space is a well-known phenomenon in a variety of animals; it parallels competition for food as a factor determining population size. A differential preference for shelters among different-sized animals may result in relaxed intraspecific competition for this resource, just as body size displacement between two species competing for the same shelters may result in a relaxation of interspecific competition.

Members of both Sphaeroma species studied can be observed to gather around piles of stones in the innermost littoral zone, and the number of isopods on each stone can be large ( 1150 on a stone measuring $21 \mathrm{~cm}$ in diameter). In aquaria, adult individuals hide in great numbers in holes made in plastic blocks. It was therefore considered likely that the isopods compete for cavities in stones and that this competition is relaxed by a displacement of body size between the two species.

The investigation consists of two parts: The first one considers field measurements in order to provide information on the distribution of different life-cycle stages on different substrates. The second one comprises an experimental study of size-dependent selection of holes.

\section{MATERIALS AND METHODS}

Sphaeroma hookeri and S. rugicauda live in shallow waters along the coasts of Western Europe. Their bio- 


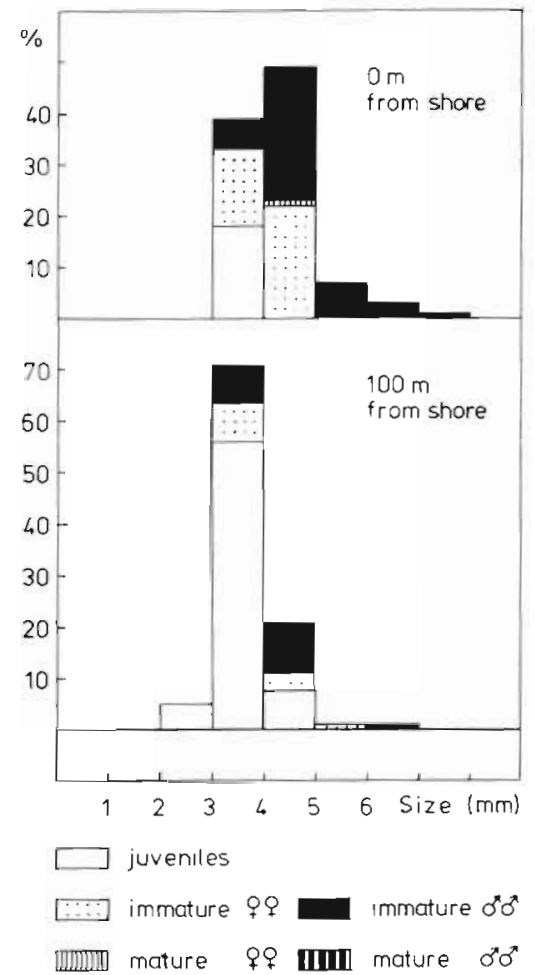

Fig. 1. Sphaeroma hookeri. Præsto Fjord. Size distribution of different stages at two different distances from the shoreline in September

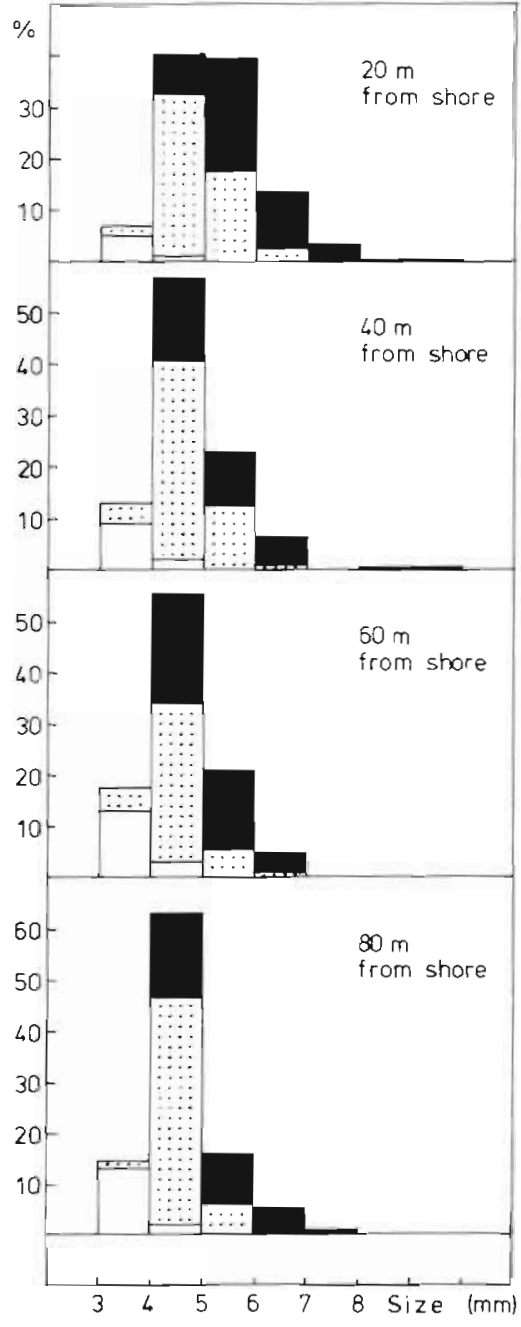

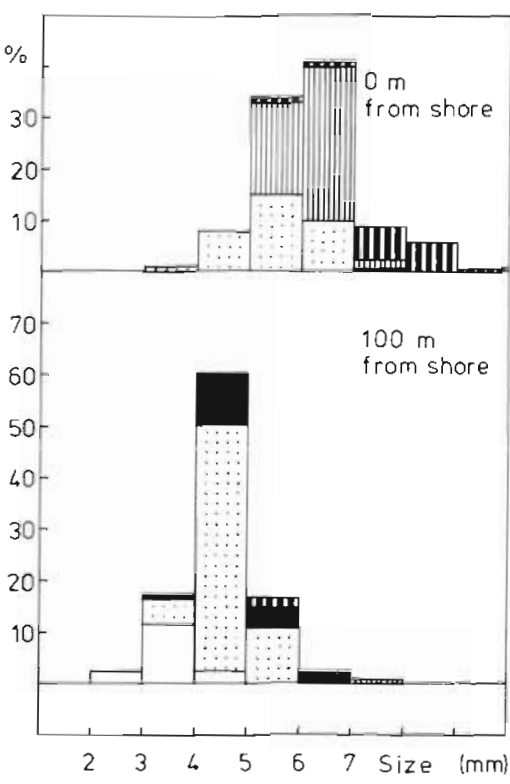

Fig. 3 (above). Sphaeroma hookeri. Præstø Fjord. Size distribution of different stages at two different distances from the shoreline in June. Designation of life-cycle stages as in Figure 1

Fig. 2 (left). Sphaeroma hookeri. Præstø Fjord. Size distribution of different stages at four different distances from the shoreline in February. Designation of life-cycle stages as in Figure 1 logy has been described by Kinne (1954), Jensen (1955) and Harvey (1969). Three major periods, each consisting of a well-defined number of instars, comprise the life cycle of these isopods. During the first 5-6 instars, individuals cannot be sexed (juvenile period). This period is followed by $2-3$ instars, during which individuals can be sexed but have not yet attained maturity (premature period). In the mature instar the males have fully developed appendices masculinae and the females carry eggs. In the present paper all individuals which could be sexed are referred to as adults (premature plus mature).

Sampling and field studies were carried out at Præstø Fjord (Sphaeroma hookeri) and Skelskør Fjord (S. nugicauda). All samplings in Præstø were carried out with a fine-meshed net pushed through heavy vegetation of Ruppia, Zostera, and Fucus species. In Skelskor the sampling substrates were collected by hand.

Experiments on hole selectivity were carried out as follows: 50,75 , or 150 individuals were chosen ran- domly from a large aquarium stock and placed in the experimental tank $(1.0 \mathrm{~m} \times 0.5 \mathrm{~m} \times 0.2 \mathrm{~m})$. The tank contained plastic blocks in which holes with diameters of $2.2 \mathrm{~mm}, 2.7 \mathrm{~mm}, 3.3 \mathrm{~mm}, 4.1 \mathrm{~mm}, 5.0 \mathrm{~mm}, 6.0 \mathrm{~mm}$, $7.4 \mathrm{~mm}$, or $9.0 \mathrm{~mm}$ had been drilled. Each diameter size was represented by 10 holes. Sand was used as an alternative substrate, and mud with diatoms as food.

The experiments lasted for a week, then the plastic blocks were removed and the size of the isopods occupying the different holes was recorded. In all experiments 6 replica were carried out for each species.

\section{RESULTS}

Figures 1-3 show the distribution of different lifecycle stages of Sphaeroma hookeri at different times of the year. Both in September and February there is a marked aggregation of adults in the innermost part of the littoral zone. This could be observed both in males and females. In June, near mating time, this distribu- 
tional pattern is especially pronounced. Special attention should be given to the fact that almost all males at the $0-\mathrm{m}$ station were mature, while the greatest part of

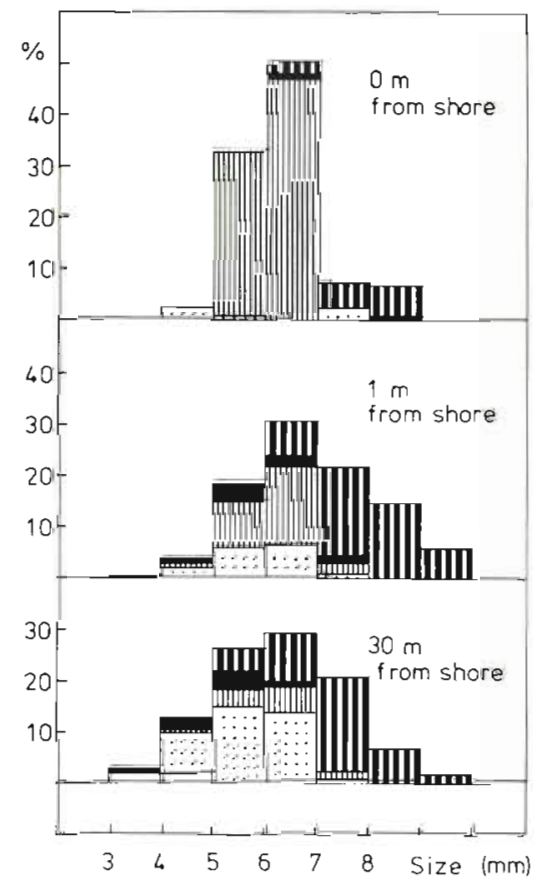

Fig. 4. Sphaeroma rugicauda. Skelskør Fjord. Size distribution of different stages at three different distances from the shoreline in June. Designation of life-cycle stages as in Figure 1. Substrate at $0-\mathrm{m}$ station: wet stones; at 1 -m station: submerged stones; at 30-m station: UIva lactuca

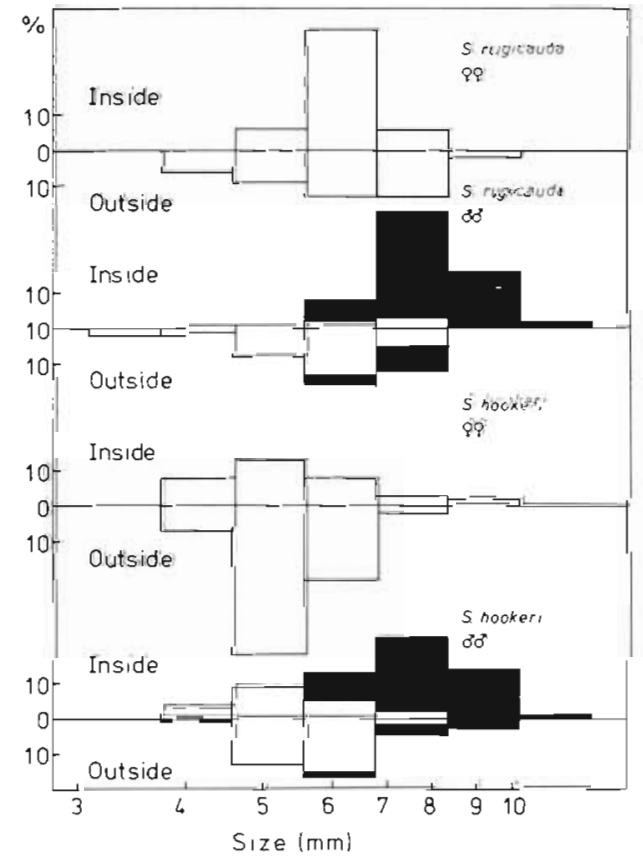

Fig. 5. Sphaeroma hookeri and S. rugicauda. Percentage of adult individuales inside and outside holes. Black blocks represent mature males. For further explanation see section Materials and Methods

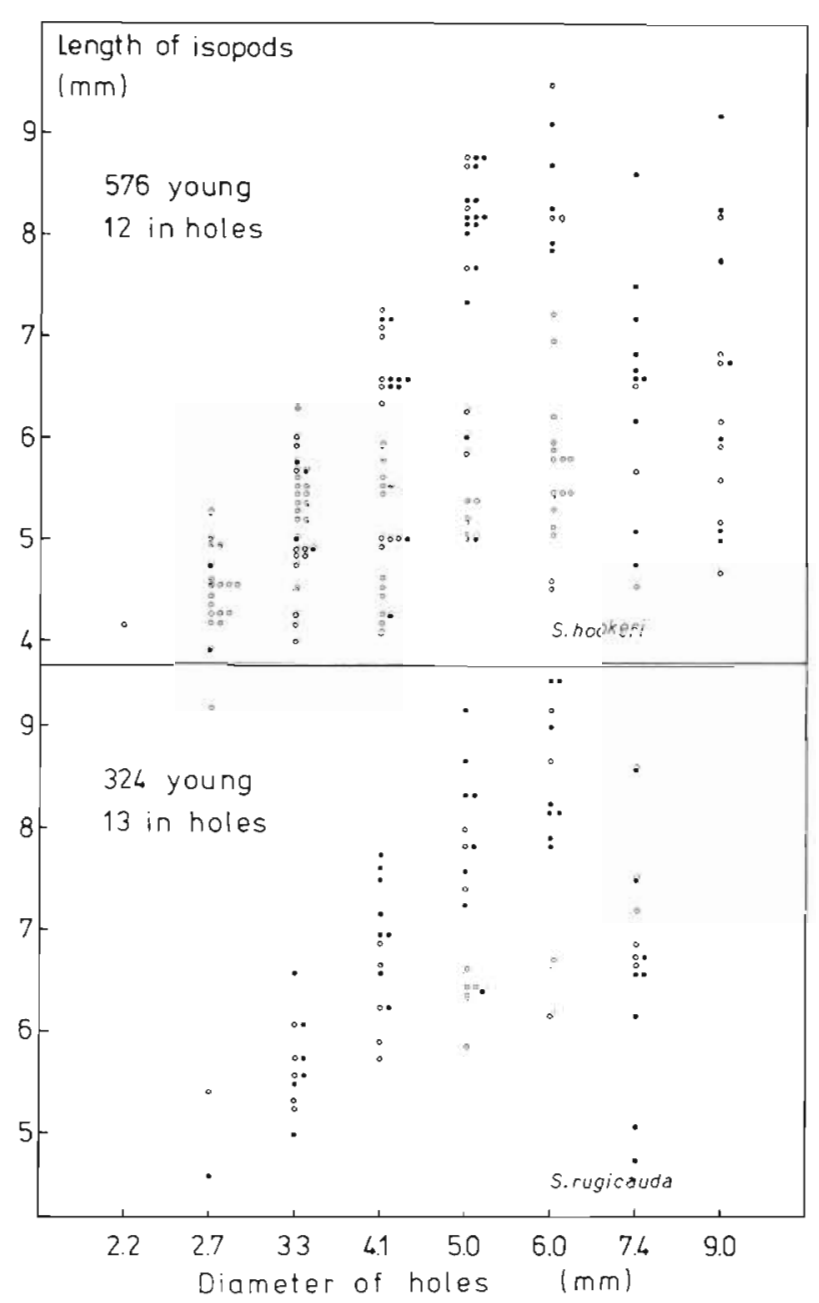

Fig. 6. Sphaeroma hookeri and $S$. rugicauda. Relation between body length and diameter of hiding holes. Black dots: males; open circles: females

those at the 100-m station were premature and not yet able to copulate. In the same way, mature females aggregated along the coast. Among the two premature molting stages in females it could be inferred from size differences that the first stage dominated at the $100-\mathrm{m}$ station, the second at the 0 -m station.

In Sphaeroma rugicauda there is also a difference in horizontal distribution of different life-cycle stages (Fig. 4). The mature females aggregated on wet stones lying on the shoreline (the station has practically no tidal fluctuations). Premature females and mature males dominated on the submerged stones just outside. At the $30-\mathrm{m}$ station, the females were - on the average - smaller, and a greater proportion of them belonged to the first premature life-cycle stage. The males are less abundant at the $30-\mathrm{m}$ station than at the 1-m station.

Figure 5 illustrates hole affinity of different life-cycle stages. Since among juveniles less than $5 \%$ were 


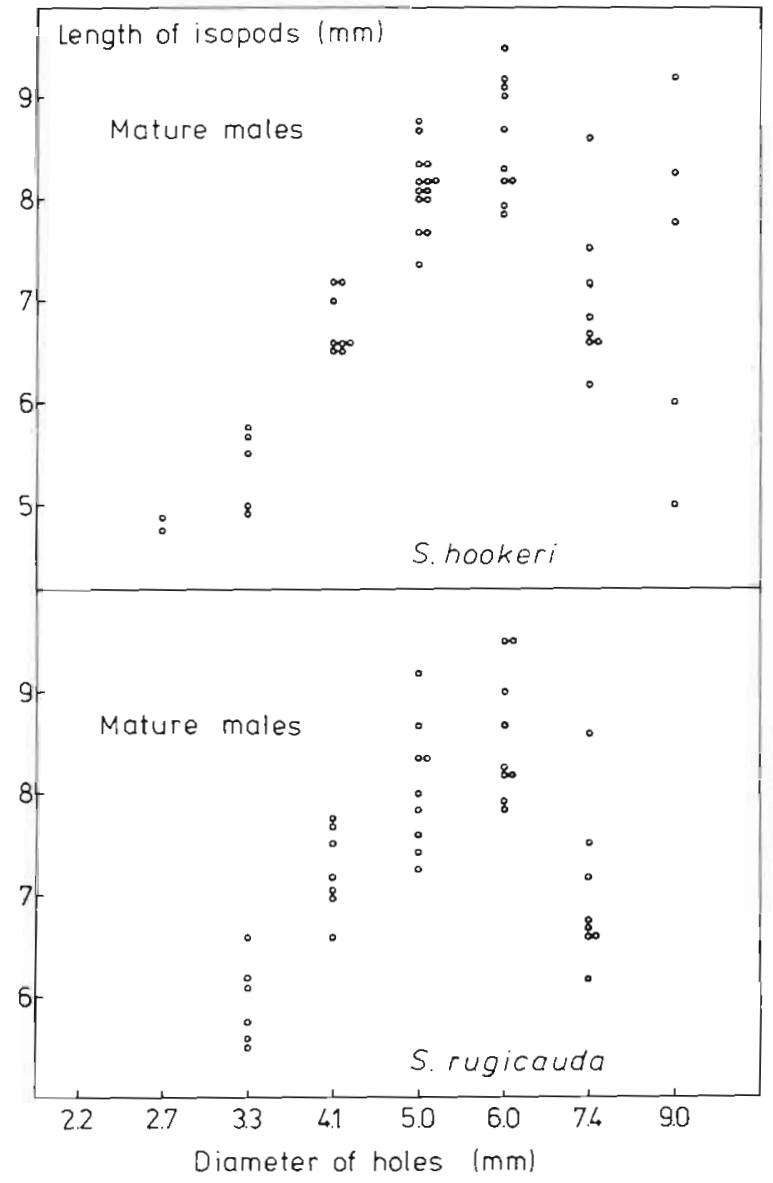

Fig. 7. Sphaeroma hookeri and S. rugicauda. Relation between length of mature males and diameter of their hiding holes

found in holes, these have been omitted. Among the adults, all stages inhabited holes in considerable numbers. Adult males exibited by far the greatest affinity for cavities and around $80 \%$ (of both species) inhabited holes. With respect to other adults groups (except premature Sphaeroma hookeri males), between $35 \%$ and $70 \%$ inhabited holes. No marked difference between the two species could be detected in this experiment.

Figures 6 and 7 show the results of experiments examining the relation between body length and hole diameter. Figure 6 documents that the data are rather confusing, although there is a well defined maximum length of isopods for each hole diameter. Taking out the individuals with the greatest affinity for holes (adult males) clarifies the picture (Fig. 7). For all holes smaller than $6 \mathrm{~mm}$ isopod length is correlated with hole diameter. Holes larger than $6 \mathrm{~mm}$ are presumably too large for any one individual, and these are inhabited by several individuals representing all length groups.

\section{DISCUSSION}

The strong tendency of adult Spaeroma to aggregate along the shoreline (Figs. 1-4) must result in considerable competition for hiding holes. Mature males (and the females they eventually carry) have a high affinity for holes (Fig. 5); this reflects their need for refuge, where they can copulate sheltered from attacks from other mature males. Figure 7 shows how males select refuges just fitting their own size. They can then totally block the entrance with their pleotelson thus avoiding fights. If isopods select too big a hole, they may eventually be pulled out by other males (unpublished observation). Given these conditions, a displacement of size between the two species (Frier, 1979a) would invariably decrease interspecific competition for shelter.

The two Sphaeroma species studied hybridize willingly in nature (Betz, 1978) and in the laboratory (unpublished results). This interaction could also be the driving force behind the divergent displacement of size and breeding time observed in sympatric populations (Frier, 1979a). The correlation between hole diameter and isopod size allows a separation of the two different-sized species on different types of substrates. This would reduce the possibility for hybridization. Furthermore, divergence in mating time would directly reduce hybridization rate. This investigation does not intend to stress the relative importance of any one of these two possibilities, but provides the necessary background for the first one.

\section{LITERATURE CITED}

Betz, K.-H. (1978). Zur Taxonomie und Biologie der beiden Isopoden Sphaeroma hookeri Leach, 1814, und Sphaeroma rugicauda Leach, 1814 (Flabellifera). Ph. D. thesis, University of Hamburg.

Daguerre de Hureaux, N. (1966). Etude du cycle biologique de Sphaeroma serratum au Maroc. Bull. Soc. Sci. nat. phys. Maroc, 46, 19-52.

Frier, J.0. (1979a). Character displacement in Sphaeroma spp. (Isopoda: Crustacea). I. Field evidence. Mar. Ecol. Prog. Ser., 1, 159-163.

Frier, J.-O. (1979b). Character displacement in Sphaeroma spp. (Isopoda: Crustacea). Hybridization between the species. In preparation.

Harvey, C. E. (1968). Breeding and distribution of Sphaeroma (Crustacea, Isopoda) in Great Britain. J. Anim. Ecol., 38, 399-406.

Jensen, J. P. (1955). Biological observations on the isopod Sphaeroma hookeri Leach. Vidensk. Meddr. dansk. naturh. Foren., 117, 305-359.

Kinne, O. (1954). Eidomie, Anatomie und Lebenszyklus von Sphaeroma hooker Leach (Isopoda). Kieler Meeresforsch., 10, 100-120. 